\title{
Quality assessment of muscle injury classification in sports: a systematic literature review
}

\author{
João Paulo C. SantAnna \\ Adriano M. de Almeida \\ André Pedrinelli \\ Arnaldo J. Hernandez \\ Tiago L. Fernandes
}

Group of Sports Medicine, Instituto de Ortopedia y Traumatologia, Hospital das Clinicas HCFMUSP, Faculdade de Medicina, Universidade de São Paulo, São Paulo, SP, Brasil

Corresponding author:

Tiago Lazzaretti Fernandes

Group of Sports Medicine, Instituto de Ortopedia y

Traumatologia

Hospital das Clínicas HCFMUSP, Faculdade de

Medicina

Universidade de São Paulo

SP. FIFA Medical Centre of Excellence - IOT HCFMUSP,

R. Dr. Ovidio Pires de Campos, 333, Cerqueira César

05403-010 São Paulo, Brazil

E-mail: tiago.lazzaretti@usp.br

\section{Summary}

Introduction: Muscular injuries are very common and lesion categorization is important for patient treatment and orientation. There is no study in literature that assessed methodological quality of classifications for muscle injury in sports. The objective of this study was to evaluate the quality of manuscripts that proposed a classification of muscular injury in sports.

Methods: A systematic search for articles in English, Spanish and Portuguese languages containing terms related to "muscle, skeletal/ injuries", "athletic injuries", "classification", "diagnosis" and "etiology" were carried out. Articles included for evaluation proposed classifications of muscular injuries related to sports and were submitted to methodological quality appraisal from Quality Assessment of Diagnostic Accuracy Studies (QUADAS-2) protocol.

Results: 1606 articles were found. From those, 17 proposed an organized system with different sorts of muscular injury. The 17 studies were graded ac- cording to methodological quality, considering risk of bias and applicability of each classification. Three studies presented very good results and one showed good results. The remaining articles presented a high or undetermined risk of bias and problems related to applicability.

Conclusion: There is a wide variety of methodological quality of classification studies. Most classifications system are only a theoretical model and therefore have important limitations. Level of evidence: Illa.

KEY WORDS: athletic injuries, bias (epidemiology), classification, muscle injury, review.

\section{Introduction}

Muscular injuries are among the most common lesions in physical activity practitioners ${ }^{1-3}$. Lesion severity categorization is a very important element for patient treatment and orientation, as well as for planning recovery time and proper rehabilitation for professional athletes and medical team department. Therefore, classification systems are important tools for guiding athletes' recovery.

Muscle injury graduation systems are mostly related to experts opinion (level of evidence V) ${ }^{4}$. These studies usually classify muscular injuries in a varied way by location, size, causative mechanism or other characteristics. Nevertheless, many Authors categorize the various aspects of these lesions but do not correlate it with a prognosis and thereby do not establish evidence to be used in the follow-up treatment for team physician.

Besides the lack of conformity between classification systems, ambiguity of technical definitions is usually present ${ }^{5}$. It disrupts communication between professionals and makes it difficult to carry out studies that evaluate the accuracy of diagnosis and prognosis provided by the proposed classification ${ }^{6}$.

Since the 1960s, studies have been published defining and classifying types of muscular injuries ${ }^{7,8}$. The number of new proposed classifications has been increasing every decade with the objective of providing a better severity understanding of these lesions and to enable prognosis standardization. On the other hand, the variety of characteristics considered in these studies has raised with the several different classification systems ${ }^{9,10}$. 
There is no study in literature that assessed methodological quality of these existing classifications. No review article could identify which classification system is based on evidence provided by well-designed protocols, low risk of bias and good applicability.

Therefore, the main objective of this study is to conduct a literature review to assess muscular injuries classification methodology, as well as graduation strengths and inadequacies.

\section{Materials and methods}

This is a systematic literature review study conducted according to PRISMA (Preferred Reporting Items for Systematic Reviews and Meta-Analysis) guidelines ${ }^{11}$. A systematic research was performed in the EMBASE, MEDLINE, PUBMED and SciELO databases from their inception to July 2017 to capture all pertinent articles investigating muscle injuries graduations. The search includes the primary and sub primary terms $(\mathrm{MeSH})$ related to "muscle, skeletal/injuries", "athletic injuries", "classification", "diagnosis" and "etiology". As several characteristics can be used to assemble a classification, this search strategy sought to cover all possible relevant studies. Search limitations were made and the full text of these studies in English, Spanish or Portuguese should be available for assessment. The searches were performed in December 2016 and updated in July 2017.

\section{Inclusion and Exclusion Criteria}

The inclusion criteria for this review were as follow: studies that proposed a classification of muscular injuries in sports were selected. The articles were included if an organized categorization of some lesionrelated feature were present. Classifications could contain etiology, topographic anatomy, physical exam findings, image aspect evaluation and others ${ }^{9,12}$.

We excluded articles that did not propose a classification or graduation of muscle injury, manuscripts that defined injury graduation not related to sports and studies that just cited an existing classification. Moreover, studies based on animal models were excluded.

\section{Study selection}

The selection of articles was performed by two Authors (TLF and JPCS) as described below. The studies selected in the databases from the pre-defined terms were merged and the duplicates were removed using Mendeley Desktop (v.1.16, Mendeley Ltd., London, UK) as shown in the flowchart based on PRISMA (Fig. 1). The studies maintained were evaluated based on their abstract and were excluded articles that did not refer to muscular injuries classifications in sports or were written in a language other than specified (English, Spanish and Portuguese) or were based on animal models or did not have full text available for assessment. In the following step, full texts of selected articles were used to assessment.
Studies that only presented an existing classification, such as update articles, systematic review, meta-analysis or case reports were excluded. Proposed ratings that were not related to sports were also removed.

After proposed classifications selection, a research was carried out to find which of them were submitted to some methodological validation. At this moment, EMBASE, PUBMED, SCIELO and MEDLINE databases were searched. We looked for articles validating classifications or researches citing the selected studies.

\section{Data extraction}

For each study meeting the inclusion criteria, descriptive information related to parameters used for categorization, sample size, subject characteristics, presence of outcomes and sports practiced were summarized using a spreadsheet from Excel (Microsoft Corporation, Redmond, Washington, USA). Information about each classification proposed and the validation study were collected and organized (Tab. I) to provide a structured summary. In addition, a summary of all 17 classifications proposed was prepared in a supplementary table (App. 1).

Each article that proposed a classification was evaluated for methodological quality by QUADAS-2 (Quality Assessment of Diagnostic Accuracy Studies) proto$\mathrm{col}^{13}$. This tool seeks to judge risk of bias in four domains (patient selection, index test performance, standard reference interpretation and patient flow) and evaluates concerns regarding to applicability of the first three domains described above. Then, 7 criteria were assessed in each study. This protocol was tailored to the research allowing more adequate evaluation ${ }^{13}$.

In order to assess the risk of bias and applicability concern, the 7 domains were evaluated on the scale "low", "high" or "unclear". To reach this result, each domain related question should be answered as "yes", "no" or "unclear" with any response other than "yes" posing a certain risk of bias or concern in applicability. All questions used in this assessment are available in the supplemental material (App. 2).

The Authors divided the studies into three categories in order to organize their assessment: (1) classification that presented validation studies; (2) classification without validation studies but presenting a clinical outcome; (3) those that did not undergo any validation method or showed no clinical outcome.

In the cases where the classifications were validated, the study evaluated by the QUADAS-2 protocol was that carried out the validation research.

Disagreement related to the use of primary and subprimary terms, exclusion of articles and assessment of selected studies were resolved by agreement between two Authors. If there was no agreement after deliberation of disagreements, a third Author was responsible for final decision. This review was approved by the local scientific committee and filed at PROSPERO (Centre for Reviews and Dissemination, University of York, UK - CRD42016039544) repository. 


\section{J. P. C. SantAnna et al.}

Appendix $1 \mathrm{~m}$ Summary of all 17 proposed classifications evaluated in the review.

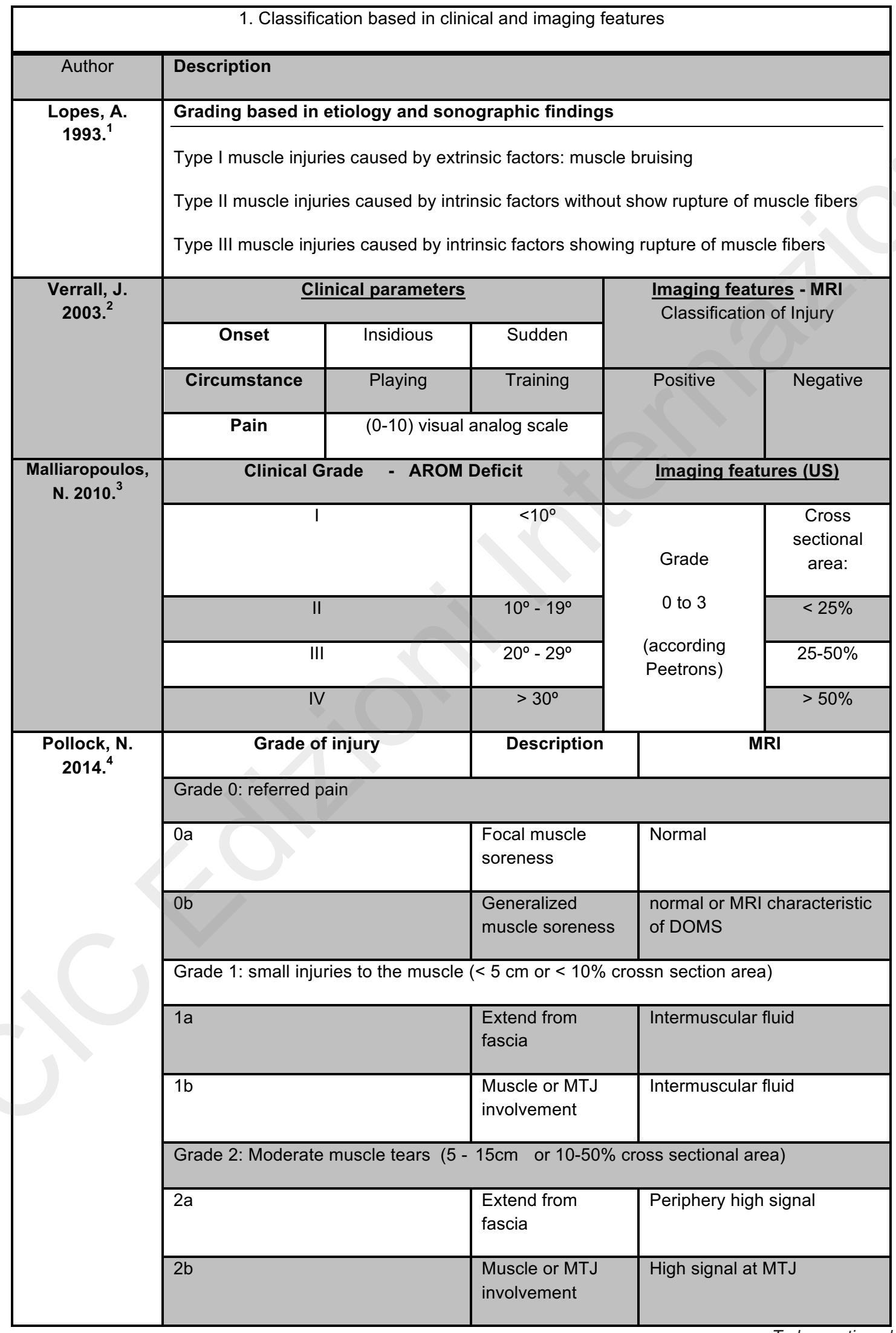


Continued from Appendix 1.

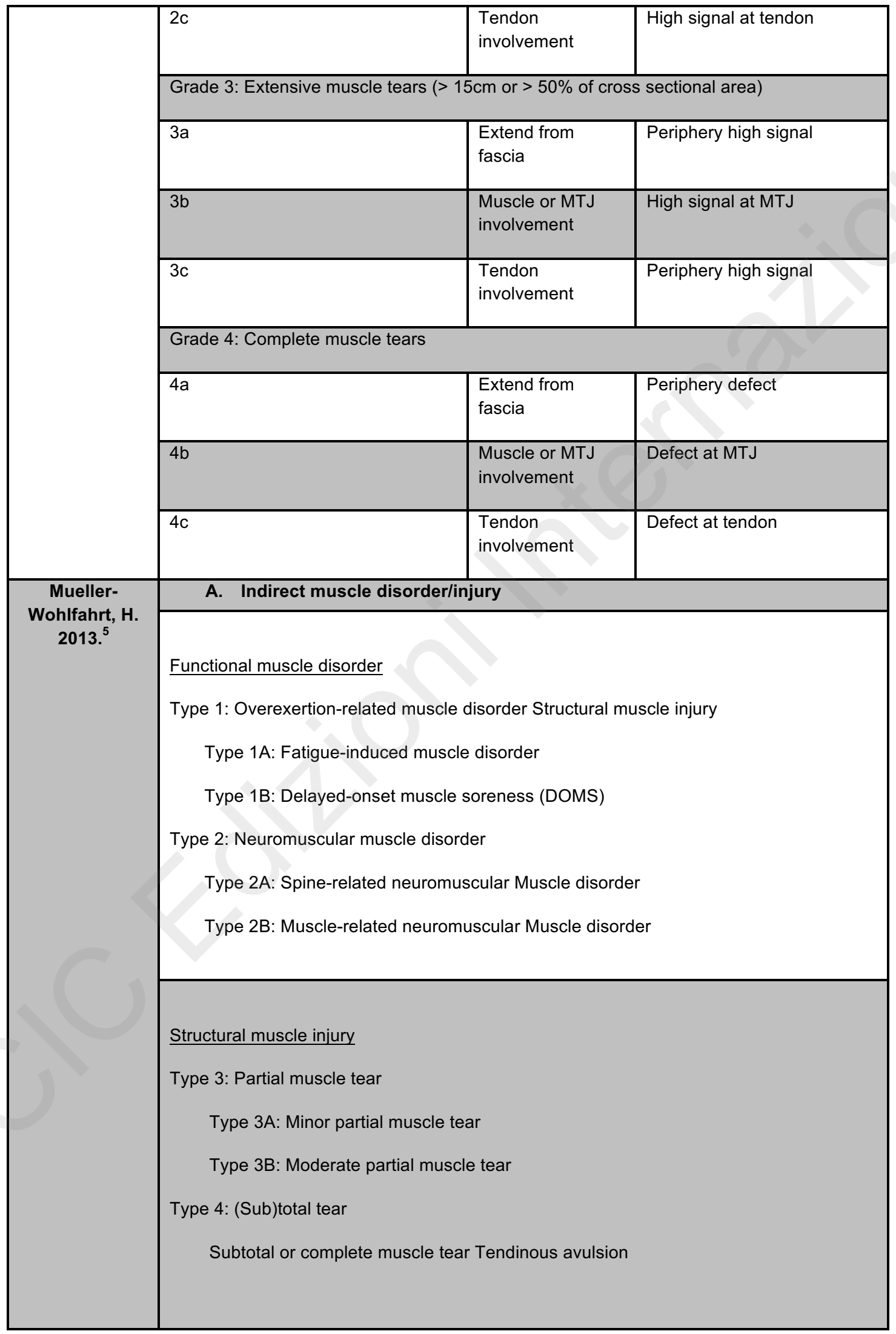

To be continued 


\section{J. P. C. SantAnna et al.}

Continued from Appendix 1.

\begin{tabular}{|c|c|}
\hline & $\begin{array}{l}\text { B. Direct muscle injury } \\
\text { Contusion } \\
\text { Laceration }\end{array}$ \\
\hline $\begin{array}{c}\text { Maffulli, N. } \\
\text { 2014. }^{6}\end{array}$ & $\begin{array}{l}\text { - Direct muscle injury } \\
\text { Contusion } \\
\text { Laceration }\end{array}$ \\
\hline
\end{tabular}

- Indirect muscle injury

$\underline{\text { Non-structural muscle injury }}$

Type 1: Fatigue muscular disorder

Type 1A: Fatigue-induced muscle disorder

Type 1B: Delayed-onset muscle soreness (DOMS)

Type 2: Neuromuscular muscle disorder

Type 2A: Spine-related neuromuscular Muscle disorder

Type 2B: Muscle-related neuromuscular Muscle disorder

\section{- Indirect muscle injury}

Structural muscle injury

Type 3: Partial muscle injury

Type 3A: Minor partial muscle tear

Type 3B: Moderate partial muscle tear $(<50 \%)$

Type 4: (Sub)total injury

Subtotal or complete muscle tear Tendinous avulsion

Structural injuries may be proximal (P), middle (M), and distal (D)

Valle, X. 2016.

\begin{tabular}{|c|c|c|c|}
\hline \multicolumn{4}{|c|}{ Clinical findings } \\
\hline $\begin{array}{l}\text { Mechanism of } \\
\text { injury (M) }\end{array}$ & Locations of injury (L) & $\begin{array}{l}\text { Grading of } \\
\text { severity (G) }\end{array}$ & $\begin{array}{l}\text { No. of muscle } \\
\text { re-injuries (R) }\end{array}$ \\
\hline $\begin{array}{l}\mathrm{T} \text { - Hamstring } \\
\text { direct injuries }\end{array}$ & $\begin{array}{l}\text { P Injury located in the proximal third } \\
\text { of the muscle belly } \\
M \text { Injury located in the middle third } \\
\text { of the muscle belly } \\
D \text { Injury located in the distal third of } \\
\text { the muscle belly }\end{array}$ & $0-3$ & $\begin{array}{l}\text { 0: 1st episode } \\
\text { 1: 1st re-injury } \\
\text { 2: } 2 \text { nd re- } \\
\text { injury ... }\end{array}$ \\
\hline $\begin{array}{l}\text { I - Hamstring } \\
\text { indirect injuries, } \\
\text { plus sub-index s } \\
\text { for stretching } \\
\text { type, or sub- } \\
\text { index p for } \\
\text { sprinting type }\end{array}$ & $\begin{array}{l}\mathrm{P} \text { Injury located in the proximal third } \\
\text { of the muscle belly. The second } \\
\text { letter is a sub-index } \mathrm{p} \text { or } \mathrm{d} \text { to } \\
\text { describe the injury relation with the } \\
\text { proximal or distal MTJ, respectively } \\
\text { M Injury located in the middle third } \\
\text { of the muscle belly, plus the }\end{array}$ & 03 & \\
\hline
\end{tabular}


Continued from Appendix 1.

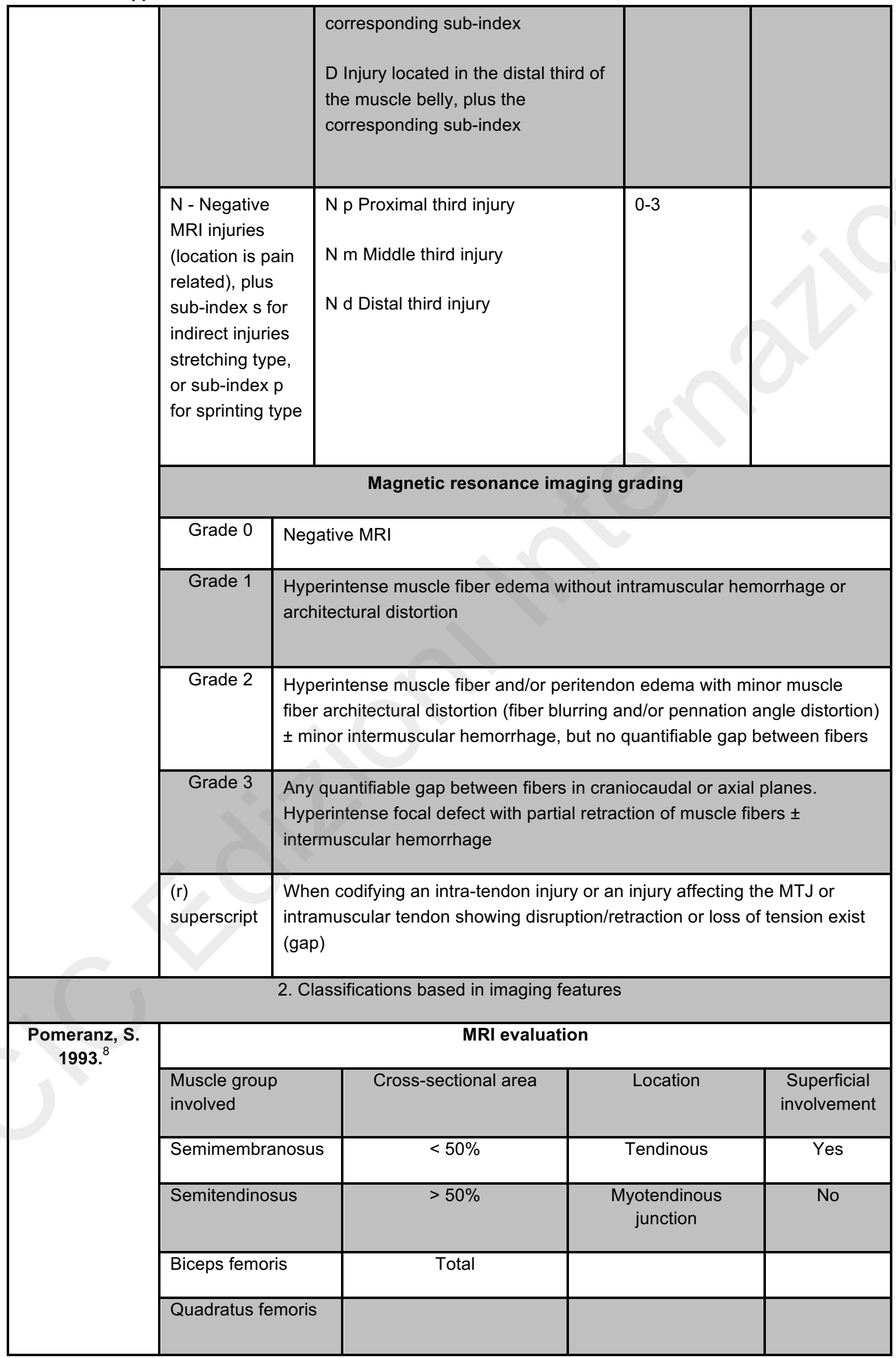

To be continued 


\section{J. P. C. SantAnna et al.}

Continued from Appendix 1.

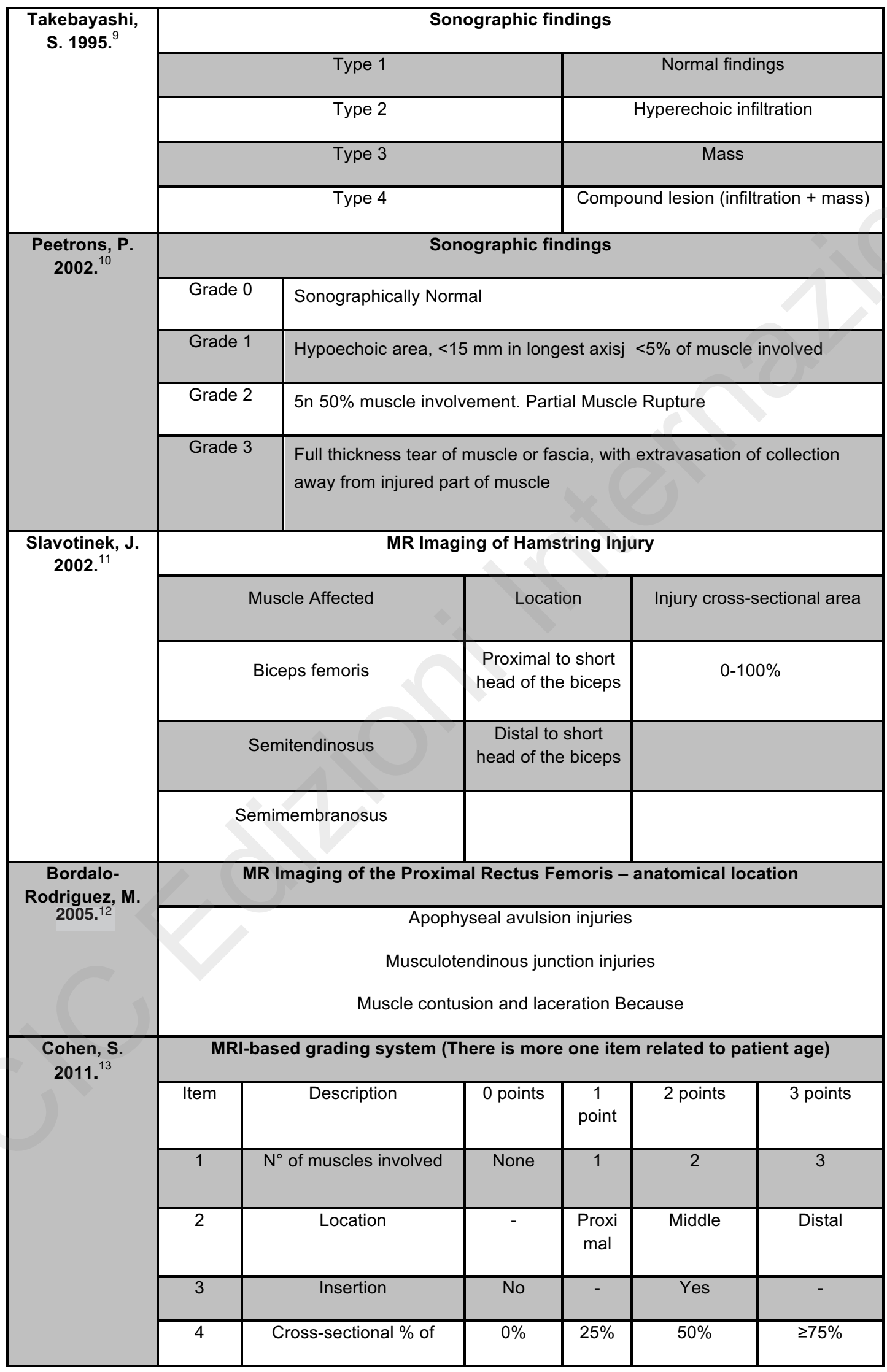


Continued from Appendix 1.

\begin{tabular}{|c|c|c|c|c|c|c|c|}
\hline & & \multicolumn{3}{|c|}{ muscle involvement } & & & \\
\hline & \multicolumn{2}{|l|}{5} & Retraction & No & - & $>2 \mathrm{~cm}$ & - \\
\hline & \multicolumn{2}{|l|}{6} & $\begin{array}{l}\text { Longitudinal axis } \\
\text { involvement }\end{array}$ & $0 \mathrm{~cm}$ & $1-5 \mathrm{~cm}$ & $6-10 \mathrm{~cm}$ & $>10 \mathrm{~cm}$ \\
\hline \multirow{5}{*}{$\begin{array}{c}\text { Chan, } 0 . \\
\text { 2012. }^{14}\end{array}$} & \multicolumn{7}{|c|}{ Grading based in radiological finding and site of lesion } \\
\hline & \multicolumn{2}{|c|}{ Grade } & \multicolumn{2}{|l|}{ MRI } & & US & Site of lesion \\
\hline & \multicolumn{2}{|c|}{ I (strain) } & \multicolumn{2}{|c|}{$\begin{array}{l}\text { Less than } 5 \% \text { of fibre disruption; } \\
\text { feathery oedema-like pattern, } \\
\text { intramuscular high signal on the } \\
\text { fluid-sensitive sequences }\end{array}$} & \multicolumn{2}{|c|}{$\begin{array}{l}\text { Normal appearance, } \\
\text { focal or general } \\
\text { increased } \\
\text { echogenicity; No } \\
\text { architectural distortion }\end{array}$} & $\begin{array}{l}\text { Proximal } \\
\text { MTJ }\end{array}$ \\
\hline & \multicolumn{2}{|c|}{$\begin{array}{l}\text { II (Partial } \\
\text { tear) }\end{array}$} & \multicolumn{2}{|c|}{$\begin{array}{l}\text { Less than } 5 \% \text { of fiber disruption; } \\
\text { feathery oedema-like pattern, } \\
\text { intramuscular high signal on the } \\
\text { fluid-sensitive sequences Oedema } \\
\text { and hemorrhage of the muscle or } \\
\text { MTJ may extend along the fascial } \\
\text { planes, between muscle groups }\end{array}$} & \multicolumn{2}{|c|}{$\begin{array}{l}\text { Muscle fibers are } \\
\text { discontinuous, the } \\
\text { disruption site is } \\
\text { hypervascularized } \\
\text { and altered in } \\
\text { echogenicity in and } \\
\text { around, with no } \\
\text { perimysial striation of } \\
\text { the area adjacent to } \\
\text { the MTJ }\end{array}$} & $\begin{array}{l}\text { Muscle } \\
\text { A. Proximal } \\
\text { B. Middle } \\
\text { C. Distal }\end{array}$ \\
\hline & \multicolumn{2}{|c|}{$\begin{array}{l}\text { III } \\
\text { (Complete } \\
\text { tear) }\end{array}$} & \multicolumn{2}{|c|}{$\begin{array}{l}\text { Complete discontinuity of muscle } \\
\text { fibers, haematoma and retraction } \\
\text { of the muscle ends }\end{array}$} & \multicolumn{2}{|c|}{ Comparable with MRI } & Distal MTJ \\
\hline \multirow{6}{*}{$\begin{array}{c}\text { Corazza, A. } \\
\text { 2013. }^{15}\end{array}$} & \multicolumn{7}{|c|}{ Combined US-MR assessment } \\
\hline & Grade & & MRI & & & US & \\
\hline & 0 & & no pathological findi & & & רo pathological & ndings \\
\hline & I & & scle edema without tiss & amage & $\begin{array}{r}\text { altere } \\
\text { tender }\end{array}$ & $\begin{array}{l}\mathrm{d} \text { echotexture a } \\
\text { ness but no sig }\end{array}$ & $\begin{array}{l}\text { the point of } \\
\text { of disruption }\end{array}$ \\
\hline & II & & partial muscle tea & & Tear & and associatec & hematoma \\
\hline & III & & complete muscle te & & & complete musc & e tear \\
\hline & & & 3. Classifications bas & clinical fi & dings & & \\
\hline Bass, A. & Classi & $\overline{\mathrm{ml}}$ & scle injuries by etiolo & ind locati & & & \\
\hline & Type & & iology & & Locatior & & \\
\hline & $\mathrm{I}$ & & rect external violence & & Intramu & scular & \\
\hline & II & & uscle contraction & & Intermu & scular & \\
\hline
\end{tabular}

To be continued 


\section{J. P. C. SantAnna et al.}

Continued from Appendix 1.

\begin{tabular}{|c|c|c|c|c|c|c|c|}
\hline \multirow[t]{8}{*}{ Wise, D. 1977.17 } & \multicolumn{7}{|c|}{ Classification based on cause, severity and location of the muscle injury in leg } \\
\hline & \multicolumn{7}{|c|}{ Indirect injuries - inflammation $\mathrm{n}$} \\
\hline & \multicolumn{7}{|c|}{ Direct injuries - trauma } \\
\hline & \multirow[t]{2}{*}{ Grade } & \multirow[t]{2}{*}{ Pain } & \multirow{2}{*}{$\begin{array}{l}\text { Circumference } \\
\text { difference }\end{array}$} & \multirow{2}{*}{$\begin{array}{c}\text { Range } \\
\text { of } \\
\text { motion }\end{array}$} & \multicolumn{3}{|c|}{ On contraction } \\
\hline & & & & & Pain & $\begin{array}{l}\text { Loss of } \\
\text { power }\end{array}$ & $\begin{array}{c}\text { Function } \\
\text { disturb }\end{array}$ \\
\hline & $\mathrm{I}$ & Minimal; & $<6 \mathrm{~mm}$ & $100 \%$ & Minimal & None & Mildly \\
\hline & II & Substantial & $6-12 \mathrm{~mm}$ & $50 \%$ & mild & mild & Great \\
\hline & III & Intractable & $>12 \mathrm{~mm}$ & $<50 \%$ & severe & $\begin{array}{c}\text { Almost } \\
\text { total }\end{array}$ & $\begin{array}{c}\text { No bear } \\
\text { weight }\end{array}$ \\
\hline & $\begin{array}{l}\text { hance } \\
\text { Inction }\end{array}$ & ge; US, ultr & und; DOMS, d & ayed on & of muscle & eness; I & \\
\hline
\end{tabular}

\section{Supplementary Appendix 1 References}

1. Lopes S, Kattan R, Costa S, Moura C. E. Estudo clínico e classificação das lesões musculares. Rev Bras Ortop. 1993;28:707-717.

2. Verrall GM, Slavotinek JP, Barnes PG, Fon GT. Diagnostic and prognostic value of clinical findings in 83 athletes with posterior thigh injury: comparison of clinical findings with magnetic resonance imaging documentation of hamstring muscle strain. Am J Sports Med. 2003;31:969-973.

3. Malliaropoulos N, et al. Posterior thigh muscle injuries in elite track and field athletes. Am J Sports Med. 2010;38:1813-1819.

4. Pollock N, James SLJ, Lee JC, Chakraverty R. British athletics muscle injury classification: a new grading system. BJ Sports Med. 2014:48:1347-1351.

5. Mueller-Wohlfahrt H-W, et al. Terminology and classification of muscle injuries in sport: the Munich consensus statement. Br J Sports Med. 2013;47:342-350.

6. Maffulli N, et al. ISMuLT Guidelines for muscle injuries. Muscles. Ligaments Tendons J. 2013;3:241-249.

7. Valle X, et al. Muscle Injuries in Sports: A New Evidence-Informed and Expert Consensus-Based Classification with Clinical Application. Sport Med. 2017;47:1241-1253.

8. Pomeranz S, Heidt JR. MR imaging in the prognostication of hamstring injury. Radiology. 1993;189:897-900.

9. Takebayashi S, et al. Sonographic findings in muscle strain injury: clinical and MR imaging correlation. J Ultrasound Med. 1995;14:899905.

10. Peetrons P. Ultrasound of muscles. Eur Radiol. 2002;12:35-43.

11. Slavotinek JP, Verrall GM, Fon GT. Hamstring injury in athletes: using MR imaging measurements to compare extent of muscle injury with amount of time lost from competition. AJR. Am J Roentgenol. 2002;179:1621-1628.

12. Bordalo-Rodrigues M, Rosenberg ZS. MR imaging of the proximal rectus femoris musculotendinous unit. Magn. Reson. Imaging Clin. N. Am. 2005;13:717-725.

13. Cohen SB, et al. Hamstring injuries in professional football players: magnetic resonance imaging correlation with return to play. Sports Health. 2011;3:423-430.

14. Chan O, Del Buono A, Best TM, Maffulli N. Acute muscle strain injuries: a proposed new classification system. Knee Surg. Sports Traumatol Arthrosc. 2012;20:2356-2362.

15. Corazza A, et al. Thigh muscles injuries in professional soccer players: a one year longitudinal study. Muscles. Ligaments Tendons J. 2013;3:331-336.

16. Bass AL. Treatment of muscle, tendon and minor joint injuries in sport. Proc R Soc Med. 1969;62:925-928.

17. Wise DD. Physiotherapeutic treatment of athletic injuries to the muscle tendon complex of the leg. Can Med Assoc J. 1977;117:635-639. 
Appendix 2 - Questions from QUADAS-2 assessment. The answers were used to help the assessment of risk of bias and concerns regarding applicability in the proposed classifications showed by studies included in the review.

\begin{tabular}{|c|c|c|c|c|c|c|c|}
\hline \multicolumn{7}{|c|}{$\begin{array}{l}\text { Domain 1: Patient Selection - Could the selection of patients have } \\
\text { introduced bias? }\end{array}$} & $\begin{array}{c}\text { Concerns } \\
\text { regarding } \\
\text { applicability }\end{array}$ \\
\hline $\begin{array}{l}\text { Was a } \\
\text { consecutive or } \\
\text { random sample } \\
\text { of patients } \\
\text { enrolled? (Yes, } \\
\text { No, Unclear) }\end{array}$ & \multicolumn{2}{|c|}{$\begin{array}{l}\text { Was a case- } \\
\text { control } \\
\text { design } \\
\text { avoided? } \\
\text { (Yes, No, } \\
\text { Unclear) }\end{array}$} & \multicolumn{2}{|c|}{$\begin{array}{l}\text { Did the study } \\
\text { avoid } \\
\text { inappropriate } \\
\text { exclusions? } \\
\text { (Yes, No, } \\
\text { Unclear) }\end{array}$} & \multicolumn{2}{|c|}{$\begin{array}{l}\text { RISK OF BIAS - } \\
\text { Could the selection } \\
\text { of patients have } \\
\text { introduced bias? } \\
\text { (Low, High, } \\
\text { Unclear) }\end{array}$} & $\begin{array}{l}\text { Is there concern } \\
\text { that the included } \\
\text { patients do not } \\
\text { match the review } \\
\text { question? (Low, } \\
\text { High, Unclear) }\end{array}$ \\
\hline \multicolumn{6}{|c|}{$\begin{array}{c}\text { Domain 2: Index Test - Could the conduct or interpretation of the } \\
\text { index test have introduced bias? }\end{array}$} & & $\begin{array}{l}\text { oncerns regarding } \\
\text { applicability }\end{array}$ \\
\hline \multicolumn{2}{|c|}{$\begin{array}{l}\text { Were the index test } \\
\text { results interpreted } \\
\text { without knowledge of } \\
\text { the results of the } \\
\text { reference standard? } \\
\text { (Yes, No, Unclear) }\end{array}$} & \multicolumn{2}{|c|}{$\begin{array}{l}\text { If a threshold } \\
\text { was used, was } \\
\text { it pre- } \\
\text { specified? } \\
\text { (Yes, No, } \\
\text { Unclear) }\end{array}$} & \multicolumn{2}{|c|}{$\begin{array}{l}\text { RISK OF BIAS - Could } \\
\text { the conduct or } \\
\text { interpretation of the } \\
\text { index test have } \\
\text { introduced bias? (Low, } \\
\text { High, Unclear) }\end{array}$} & & $\begin{array}{l}\text { ere concern that the } \\
\text { ex test, its conduct, } \\
\text { interpretation differ } \\
\text { from the review } \\
\text { estion? (Low, High, } \\
\text { Unclear) }\end{array}$ \\
\hline
\end{tabular}

Domain 3: Reference Standard - Could the reference standard, its conduct, or its interpretation have introduced bias?

\section{Concerns regarding} applicability

RISK OF BIAS: Could the reference standard, its conduct, or its interpretation have introduced bias? (Low, High, Unclear)
Is there concern that the target condition as defined by the reference does not match the review question? (Low, High, Unclear)

Domain 4: Flow and timing - Could the patient flow have introduced bias?

Did all

Was there an patients appropriate interval receive a between index test reference and reference standard?

Did all patients receive the same reference standard? (Yes, No, Unclear)
(Yes, No, Unclear) standard? (Yes, No, Unclear)
Were all patients included in the analysis? (Yes, No, Unclear)
RISK OF BIAS Could the patient flow have introduced bias? (Low, High, Unclear) 


\section{J. P. C. SantAnna et al.}

\section{Results}

Using the defined strategies, 1805 articles were found corresponding to primary and sub-primary terms (MeSH and DeCS) related to "muscle, skeletal/injuries", "athletic injuries", "classification", "diagnosis" and "etiology" from the selected databases.

After exclusion of duplicate items, 1606 articles were maintained and their abstracts were evaluated. 1562 texts were excluded due to not refer to muscular injuries graduation or not be related to sports, or they were written in another language different from those proposed or were based on animal model or did not have a full text available. Forty-four articles presented some classification of muscular injuries in sports and full text was evaluated (Fig. 1).

The 44 studies selected for the second stage included 17 articles that proposed a new classification. The other 27 articles presented studies of case report, reviews showing updates, overview of evaluation strategies, treatment of muscle injuries or exposed ratings related to non-sports activity.

Characteristics of the proposed classifications and some features from the studies assessed for methodological quality are showed in Table I. These features, like patient involvement, presence of target condition or clinical outcome were extracted from the data of the studies evaluated in QUADAS-2 protocol. As previously stated, in the cases where classifications were validated, we evaluated the validity study. Among 17 studies with classifications of muscle injury in sports, two articles published by Bass et al. in 1969 and Wise et al. in $1977^{8,14}$ presented classifications based just on clinical findings. The first classification based only on image was published in 1993 by Pomeranz et al. ${ }^{15}$ and eight classifications in total took into account only aspects of image exam ${ }^{15-22}$.

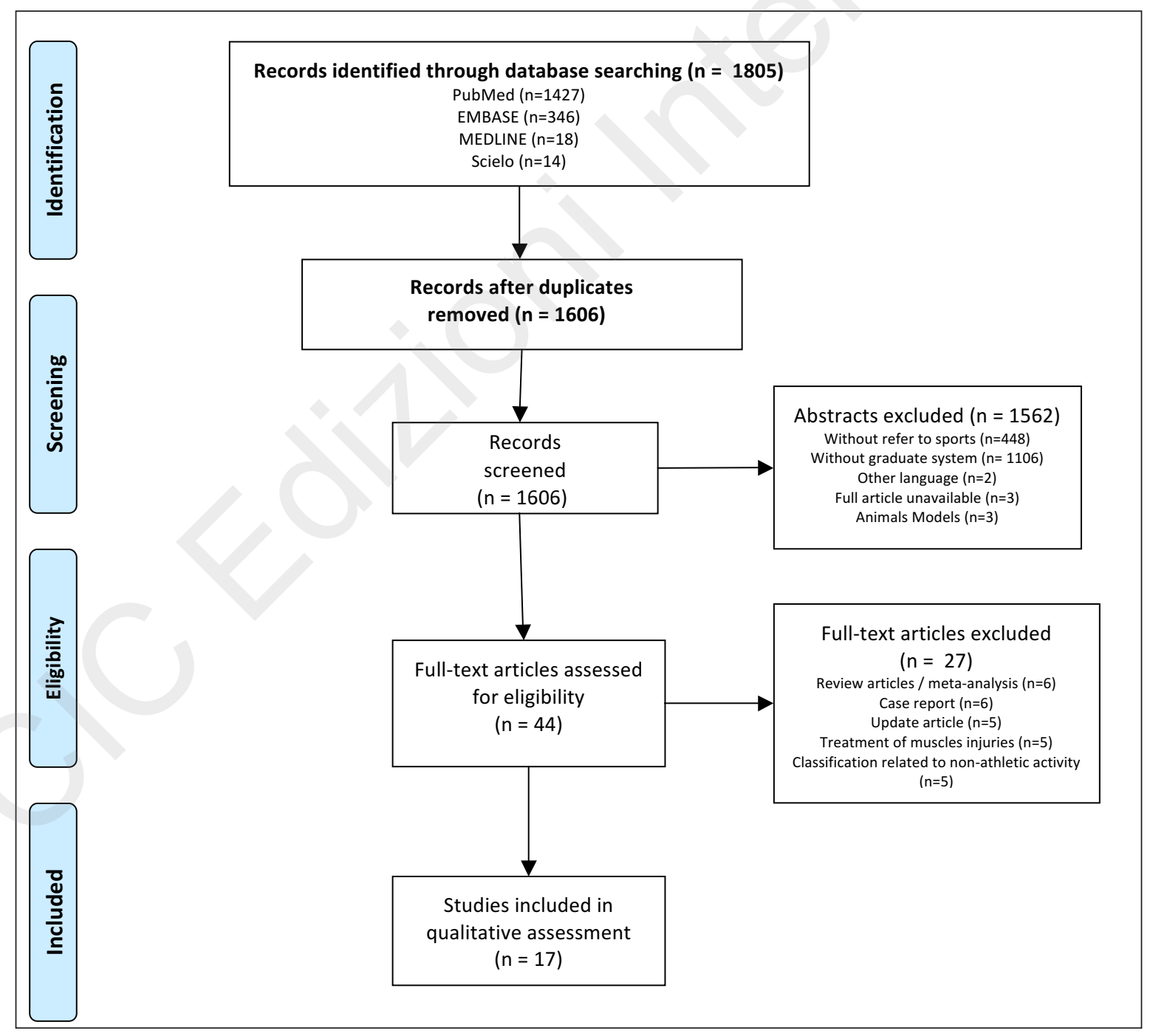

Figure 1. Flowchart of literature search process. 
Seven graduation systems were based on clinical and radiological findings $\mathrm{s}^{6,23-28}$.

Regarding some features used for methodological evaluation, six classifications had no study with patients to assess whether the proposed graduation correlated with clinical and radiological findings $8,14,19,21,27,28$. Among 11 studies that evaluated patients, 4 involved soccer players $22,24,29,30,2$ included Australian football (Australian rules) players ${ }^{18,25}, 2$ involved athletics ${ }^{26,31}$, 1 with football (American football) players ${ }^{20}$ and 2 involving sportsman without definition of sport ${ }^{19,21}$.

The athletes largest study was conducted in Brazil and published in 1993 by Lopes et al. ${ }^{24}$ in which 2670 soccer players were evaluated (Table I).

The most frequently assessed muscle group was hamstrings. Eight studies evaluated hamstring injuries isolated ${ }^{15,18,20,25-27,29,31}$, while 3 studies included more muscle groups: Corazza et al. ${ }^{22}$ and Ekstrand et al. ${ }^{30}$ assessed injuries of the thigh and Takebayashi et al. ${ }^{17}$ assessed hamstrings, quadriceps and calves. One study evaluated lesions of the rectus femoris muscle ${ }^{19}$ and the 5 other studies did not define which muscle group were evaluated $8,14,21,24,28$.

Regarding to clinical outcome, in 8 studies it wasn't assessed $8,14,19,21,24,28,31$. The other 9 studies reached a clinical endpoint and return to sports was the chosen target condition in all these research.

As described before, 17 studies were selected to be evaluated by QUADAS-2 protocol. Three classifications presented validation study in literature ${ }^{6,16,23}$. Ekstrand et al. ${ }^{29}$ validated the classification described by Peetrons ${ }^{16}$; the Munich consensus statement ${ }^{23}$ was validated through a study from Ekstrand et al. ${ }^{30}$ and the British athletics muscle injury classification system ${ }^{6}$ was validated from the study of Patel et al. ${ }^{31}$. The results of QUADAS-2 were summarized in a tabular presentation (Fig. 2). In patient selection domain, 7 studies ${ }^{18,22,25,26,29-31}$ presented low risk of bias and the other 10 had high or unclear risk of bias. In each of the other 3 domains (index test, reference standard, flow and timing) less than $1 / 3$ presented low risk of bias. Five studies with low risk of bias in index test ${ }^{17,18,29-31}$, and 4 studies with low risk of bias both in reference standard and flow and timing domain 17,29-31. Regarding to applicability concerns 10 studies showed low concern in patient selection domain, 11 in index test, and 5 showed low applicability concern in reference standard domain. QUADAS-2 assessment showed less than half of all proposed classifications studies had low risk of bias in all domains, whereas more than a half studies presented low applicability concern in 2 of 3 domains (Fig. 3 ). When the articles were divided into the 3 groups described in methods, it was found 3 classifications $6,16,23$ in the first group as shown above. The second group formed by graduations without validation studies but that presented clinical outcome consisted of 7 studies $15,17,18,20,22,25,26$. The remaining seven studies formed the third group $8,14,19,24,27,28,32$.
The articles in the second and third groups presented a high risk of bias and problems related to applicability in almost all domains evaluated in comparison to the first group composed by validity studies as shown in the tabular presentation (Fig. 2).

\section{Discussion}

Sports muscle injury is increasingly studied and discussed in scientific publications ${ }^{9}$. It is verified due to 1606 articles from this present search strategy. Most studies did not meet the inclusion criteria, but these numbers show how this issue has become common. Almost half of the evaluated graduations were published in the last decade. There were 8 different rating systems presented between 2010 and $2016^{6,20,22,23,26-28,32}$, of the 17 articles published since the 1960s. The increase in sports practice, both professional and amateur may be one of the factors stimulating the rise of research in this field. In addition to this, the costs related to a professional athlete absence from training and matches have stimulated the study of muscular injuries. Another important reason that leads research groups to develop new classification systems may be the lack of methodological quality of previous studies.

Regarding general characteristics assessed, all classifications except two $0^{8,14}$ are based on image studies. These imaging protocols have been shown to be important in diagnosis and prognosis, and new studies aim to improve the correlation findings between images and injury severity and return to sports. Most of the studies evaluated limited muscle groups, which most often were hamstrings. This delimitation is necessary and seeks to standardize research, allowing Authors to reach their outcomes properly. Furthermore, Authors classify muscle injury by many others aspects such as location, size, causative mechanism and other characteristics. The use of these different features can create misunderstanding when we try to compare muscle injuries severity trough distinct classifications.

In this review we noted 13 researchers classified muscle lesions seeking to correlate the graduation with a target condition such as return to sports activity $8,15-18,20,22-28$. But just 9 studies sought to define a clinical outcome $15-18,20,22,23,25,26$. Thus, almost half of studies did not established valid evidence that could guide the team physician in muscle injury treatment. This lack of outcome evaluation can create systems that had poor applicability.

QUADAS-2 protocol was used in this review to evaluate the methodology of the studies. As described before, we divided the studies into 3 groups. The first group, formed for researches that not just implemented or assessed a graduation system, but also validated and evaluated its predictive value for a clinical outcome, presented the best result of methodological quality, with low risk of bias in all domains evaluated. The studies of the other 2 groups (without validation 


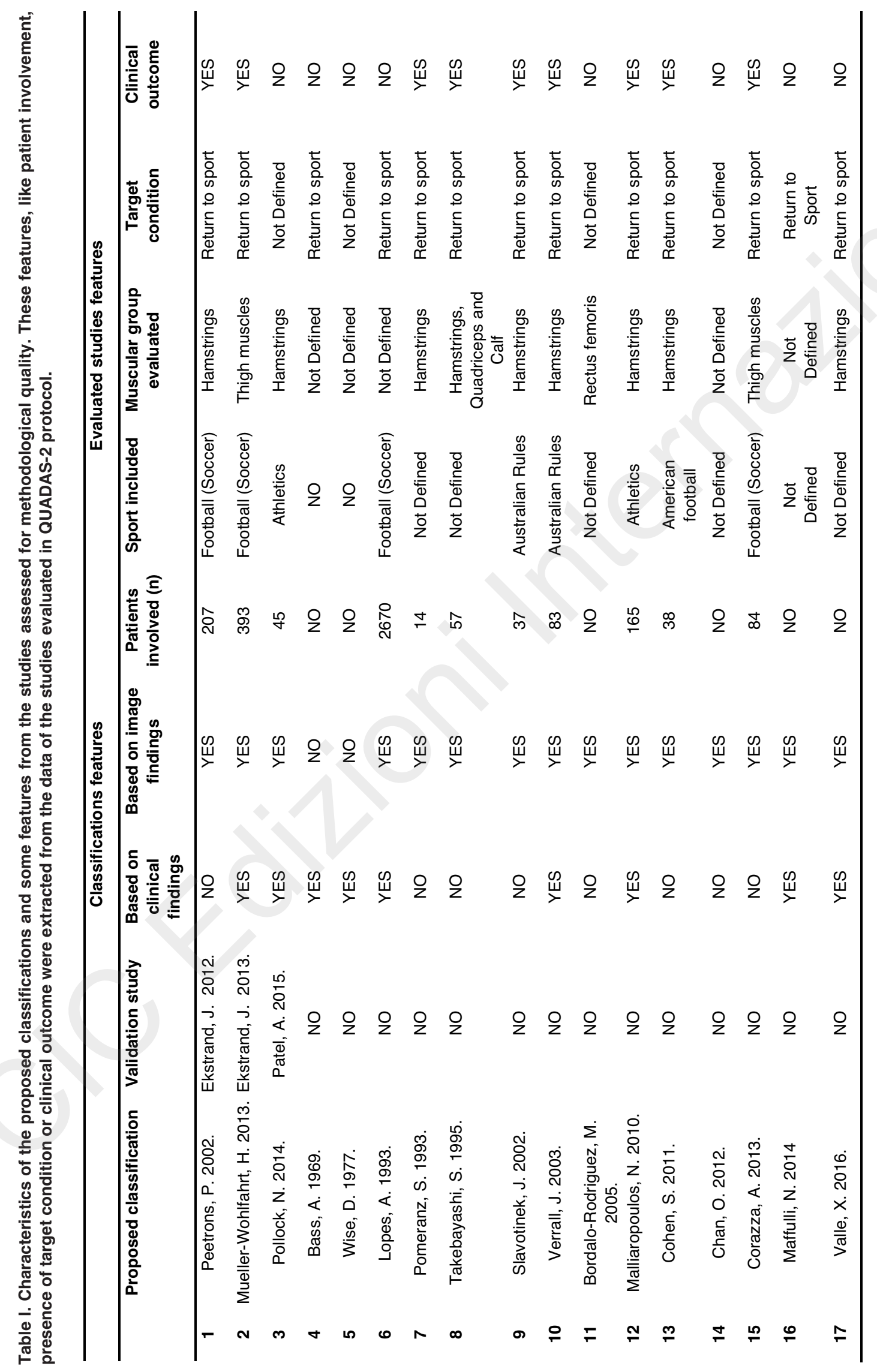




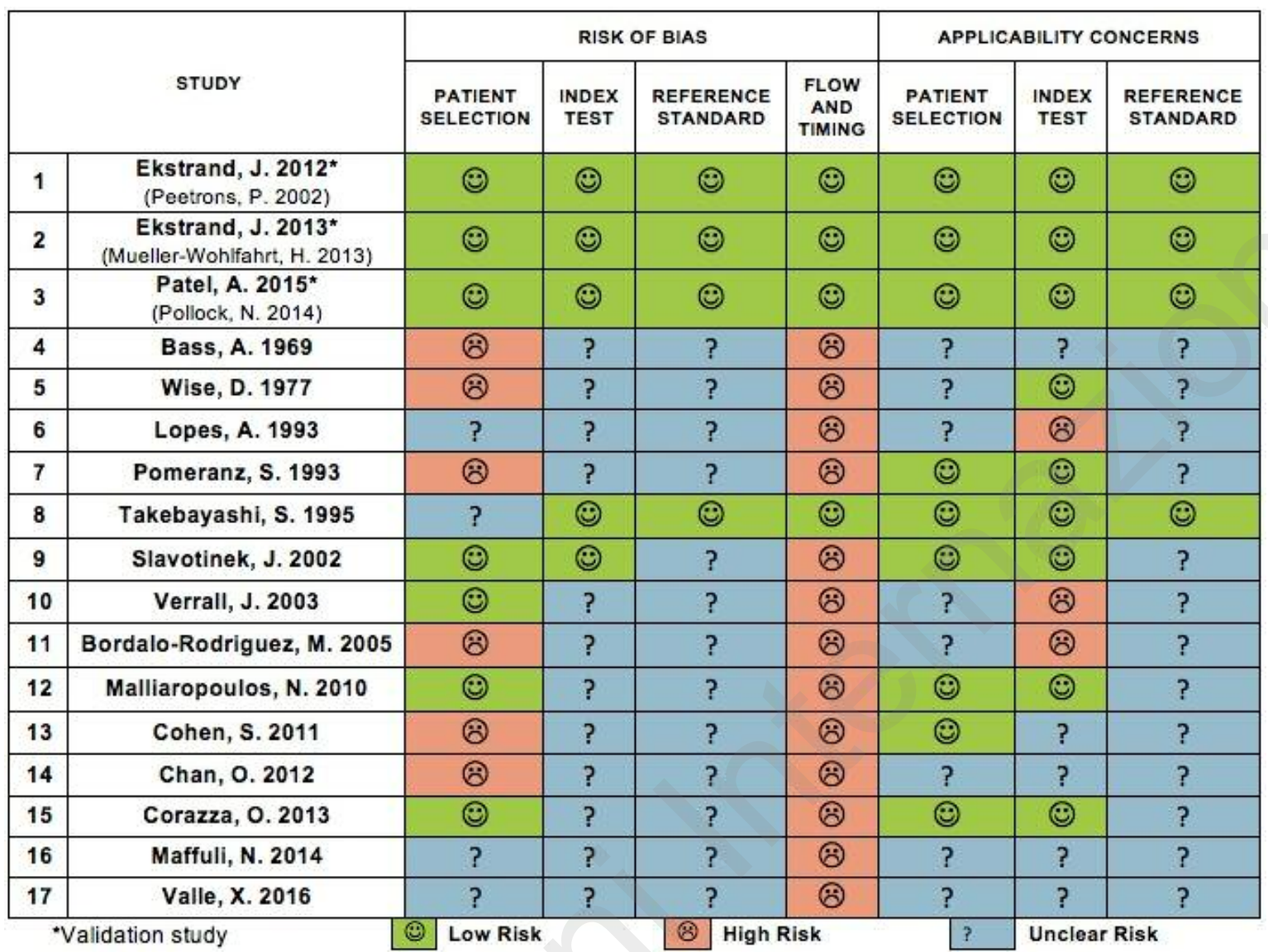

Figure 2. QUADAS protocol results summarized in a tabular presentation showing the high prevalence of studies with undertemined and high risk of bias.

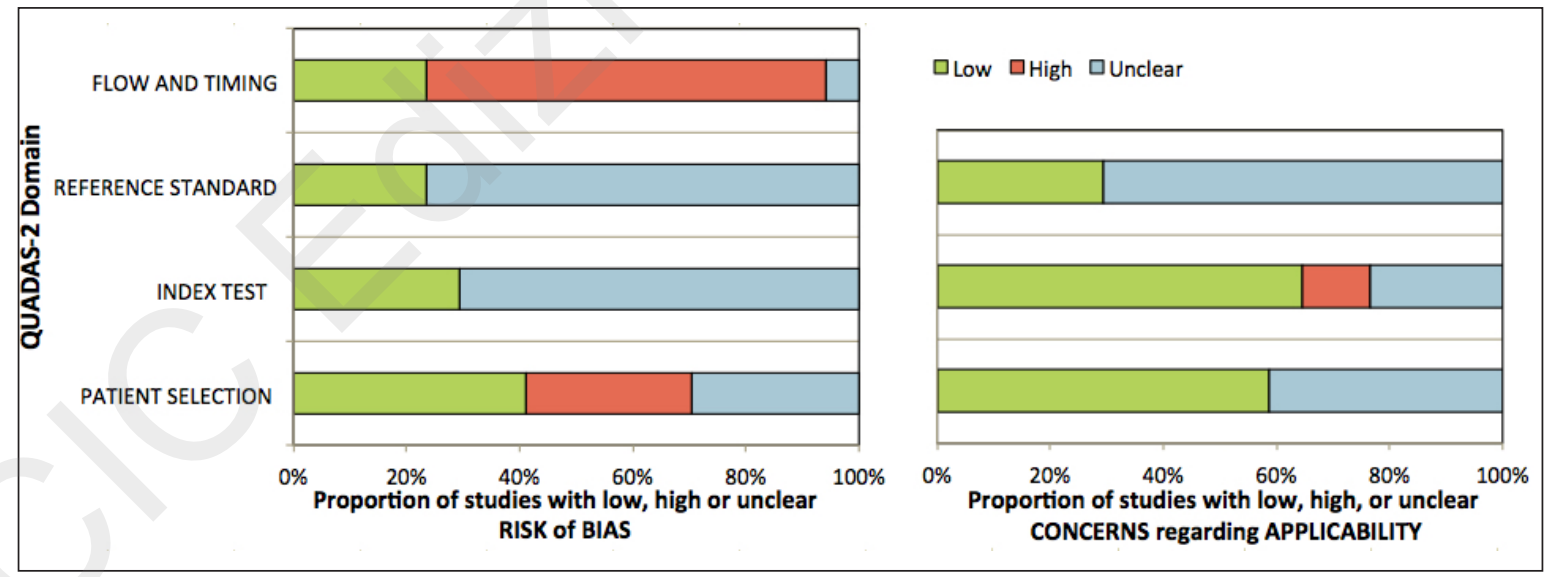

Figure 3. Percentage results of QUADAS protocol assessment shows less than half of classifications presented studies with low risk of bias in all domains. In majority of domains an undetermined or high risk of bias was present.

study) showed a risk of high bias in at least 1 of the 4 domains assessed.

It is interesting to notice that about $70 \%$ of these studies presented an undetermined bias towards the index test performance and the standard reference interpretation. This difficulty in accurately determining the risk of bias in several studies was a complication for this review article. However, it was expected that the large number of classifications created without adequate methodology to assess their reliability could lead to this limitation.

Nevertheless, the initial hypothesis that muscle injury classification studies have a low level of compliance could be confirmed. There is a wide variety of metho- 
dological quality of most classification studies. Most classifications are only a theoretical model and therefore have important limitations.

Previous reviews also shown the wide variety in how to graduate muscle injuries $5,33,34$. Two narrative reviews show the methods used for creating various classification systems chronologically ${ }^{5,33}$. Nevertheless, no review evaluated systematically the methodological quality of these existing classifications and sought to define which systems were based on evidence from well-designed studies with low risk of bias and good applicability.

We could conclude that excellent methodological quality is an important issue and it should be sought for every study based on diagnostic accuracy. It is proposed that studies related to muscle injury classification in sports should be performed looking for better prognosis predicting. In this study, the classifications proposed by Peetrons ${ }^{16}$, Mueller-Wohlfahrt ${ }^{23}$ and Pollock ${ }^{6}$ were very well evaluated, presenting good results regarding risk of bias and applicability. In our clinical practice we use the Munich consensus statement, this system seems to be simple in its application and covers the wide range of muscle lesions found in our practice. Moreover, it is a useful tool regarding the challenging of predict return to sports for the injured player.

Finally, it is certain that most of the researchers are searching to define a graduation of muscle injury that could be used for different muscle groups. Nevertheless, the studies published so far do not allow such possibility. Each muscle groups are required in different ways and the mechanisms of injury and recovery time may vary for each group. The complexity of muscle injury appears to be the main reason for the difficulty of create a simple system with an excellent correlation to clinical outcomes. It would require plenty of clinical research with appropriate methodology and comparative analysis of the assessment of individualized sports and specific muscle group.

\section{Acknowledgements}

The main Author (JPCS) and the corresponding Author (TLF) performed the search and wrote the article. All Authors contributed to reviewing the manuscript, agree on the final draft, and take responsibility for the integrity of the data and accuracy of the analysis performed. The Authors did not receive financial assistance to perform the current review.

\section{Ethics}

The Authors declare that this research was conducted following basic ethical aspects and international standards as required by the journal and recently update $\mathrm{in}^{35}$.

\section{References}

1. Ekstrand J, Hägglund M, Waldén M. Epidemiology of Muscle Injuries in Professional Football (Soccer). Am J Sports Med. 2011 Jun 18;39(6):1226-32. Available from: http://journals. sagepub.com/doi/10.1177/0363546510395879

2. Alonso J-M, Edouard P, Fischetto G, Adams B, Depiesse F, Mountjoy M. Determination of future prevention strategies in elite track and field: analysis of Daegu 2011 IAAF Championships injuries and illnesses surveillance. $\mathrm{Br} \mathrm{J}$ Sports Med. England. 2012 Jun;46(7):505-514.

3. Fernandes TL, Pedrinelli A, Hernandez AJ. Lesao muscular Fisiopatologia, diagnostico, tratamento e apresentacao clinica. Rev Bras Ortop. 201146(3):247-255. Available from: http://www.scielo. br/pdf/rbort/v46n3/a03v46n3.pdf

4. Heneghan C, Badenoch D. Evidence-Based Medicine Toolkit. 2nd Ed. Wiley Blackwell. 2006.

5. Hamilton B, Valle X, Rodas G, Til L, Pruna Grive R, Gutierrez Rincon JA, et al. Classification and grading of muscle injuries: a narrative review. Br J Sports Med. 2015 Mar;49(5):306-306. Available from: http://bjsm. bmj.com/lookup/doi/10.1136/bjsports-2014-093551

6. Pollock N, James SLJ, Lee JC, Chakraverty R. British athletics muscle injury classification: a new grading system. Br J Sports Med. England; 2014 Sep;48(18):1347-1351.

7. Rachun A. Standard nomenclature of athletic injuries. Standard nomenclature of athletic injuries. 1st Ed. Chicago, IL American Medical Association. 1966:157.

8. Bass AL. Treatment of muscle, tendon and minor joint injuries in sport. Proc R Soc Med. England. 1969 Sep;62(9):925-928.

9. Hamilton B, Alonso J-M, Best TM. Time for a paradigm shift in the classification of muscle injuries. J Sport Heal Sci. 2017; Available from: http://ac.els-cdn.com/S2095254617300650/1s2.0-S2095254617 300650-main.pdf?_tid=59425208-8c6211 e7-bedf- 00000 aab 0f $26 \&$ acdnat $=1503974150$ d46a294f4e 17f60ab5e006860d84522b

10. Reurink G, Brilman EG, de Vos R-J, Maas M, Moen MH, Weir A, et al. Magnetic Resonance Imaging in Acute Hamstring Injury: Can We Provide a Return to Play Prognosis? Sport Med. 2015 Jan 1545(1):133-146. Available from: http://link.springer. com/10.1007/s40279-014-0243-1

11. Liberati A, Altman DG, Tetzlaff J, Mulrow C, Gøtzsche PC, loannidis JPA, et al. The PRISMA statement for reporting systematic reviews and meta-analyses of studies that evaluate health care interventions: explanation and elaboration. PLoS Med. Public Library of Science. 2009 Jul 21;6(7):e1000100. Available from: http://journals. plos.org/plosmedicine/article? id $=10.1371$ journal.pmed. 1000100

12. Hagglund $M$. Methods for epidemiological study of injuries to professional football players: developing the UEFA model. $\mathrm{Br}$ J Sports Med. 2005;39(6):340-346. Available from: https://www.ncbi.nlm.nih.gov/pmc/articles/PMC1725241/pdf/ v039p00340.pdf

13. Whiting PF, Rutjes AWS, Westwood ME, Mallett S, Deeks JJ, Reitsma JB, et al. QUADAS-2: a revised tool for the quality assessment of diagnostic accuracy studies. Ann Intern Med. American College of Physicians. 2011 Oct 18;155(8):529-536. Available from: http://annals. org/article.aspx?articleid $=474994$

14. Wise DD. Physiotherapeutic treatment of athletic injuries to the muscle-tendon complex of the leg. Can Med Assoc J. 1977 Sep 17;117(6):635-639. Available from: http://www.pubmedcentral.nih.gov/articlerender.fcgi? artid=1879858\&tool=pmcentrez\&rendertype=abstract

15. Pomeranz S, Heidt Jr. R. MR imaging in the prognostication of hamstring injury. Radiology. US 1993 Dec;189(3):897-900. 
16. Peetrons P. Ultrasound of muscles. Eur Radiol. 2002;12(1): 35-43.

17. Takebayashi $\mathrm{S}$, Takasawa $\mathrm{H}$, Banzai $Y$, Miki H, Sasaki R, Itoh $Y$, et al. Sonographic findings in muscle strain injury: clinical and MR imaging correlation. J Ultrasound Med. 1995 Dec 1;14(12):899-905. Available from: http://www.jultrasoundmed. org/content/14/12/899.abstract

18. Slavotinek JP, Verrall GM, Fon GT. Hamstring injury in athletes: using MR imaging measurements to compare extent of muscle injury with amount of time lost from competition. AJR Am J Roentgenol. American Roentgen Ray Society; 2002 Dec 23;179(6):1621-1628. Available from: http://www.ajronline. org/doi/abs/10.2214/ajr.179.6. 1791621

19. Bordalo-Rodrigues M, Rosenberg ZS. MR imaging of the proximal rectus femoris musculotendinous unit. Magn Reson Imaging Clin N Am. United States. 2005 Nov;13(4):717-725.

20. Cohen SB, Towers JD, Zoga A, Irrgang JJ, Makda J, Deluca $\mathrm{PF}$, et al. Hamstring injuries in professional football players: magnetic resonance imaging correlation with return to play. Sports Health. 2011 Sep;3(5): 423-430. Available from: http://www.pubmedcentral. nih.gov/articlerender.fcgi?artid $=3445213 \&$ tool=pmcentrez\&rendertype $=$ abstract

21. Chan O, Del Buono A, Best TM, Maffulli N. Acute muscle strain injuries: a proposed new classification system. Knee Surg Sports Traumatol Arthrosc. 2012 Nov;20(11):2356-2362. Available from: http://www. ncbi.nlm.nih.gov/pubmed/ 22773066

22. Corazza A, Orlandi D, Baldari A, Gatto P, Stellatelli M, Mazzola $\mathrm{C}$, et al. Thigh muscles injuries in professional soccer players: a one year longitudinal study. Muscles Ligaments Tendons J. CIC Edizioni Internazionali. 2013 Oct;3(4):331-336. Available from: http://www.ncbi. nlm.nih.gov/pubmed/ 24596698

23. Mueller-Wohlfahrt H-W, Haensel L, Mithoefer K, Ekstrand J, English B, McNally S, et al. Terminology and classification of muscle injuries in sport: the Munich consensus statement. $\mathrm{Br} \mathrm{J}$ Sports Med. England. 2013 Apr;47(6):342-350.

24. Lopes a. S, Kattan R, Costa S, Moura CE. Estudo clínico e classificação das lesões musculares. Rev Bras Ortop. 1993;28(10):707-717. Available from: http://www.rbo.org.br/ PDF/28-7/1993_out_07.pdf

25. Verrall GM, Slavotinek JP, Barnes PG, Fon GT. Diagnostic and Prognostic Value of Clinical Findings in 83 Athletes with Posterior Thigh Injury: Comparison of Clinical Findings with Magnetic Resonance Imaging Documentation of Hamstring Muscle Strain. Am J Sport Med. 2003 Nov 1;31(6):969-973. Available from: http://ajs. sagepub.com/cgi/content/short/ 31/6/969
26. Malliaropoulos N, Papacostas E, Kiritsi O, Papalada A, Gougoulias N, Maffulli N. Posterior thigh muscle injuries in elite track and field athletes. Am J Sports Med. 2010 Sep 1;38(9): 1813-1819. Available from: http://ajs.sagepub.com/ cgi/content/short/38/9/1813

27. Valle X, Alentorn-Geli E, Tol JL, Hamilton B, Garrett WE, Pruna R, et al. Muscle Injuries in Sports: A New Evidence-Informed and Expert Consensus-Based Classification with Clinical Application. Sport Med. 2017 Jul 23;47(7):1241-1253. Available from: http://link.springer. com/10.1007/s40279-0160647-1

28. Maffulli N, Oliva F, Frizziero A, Nanni G, Barazzuol M, Via AG, et al. ISMuLT Guidelines for muscle injuries. Muscles Ligaments Tendons J. CIC Edizioni Internazionali; 2013 Oct;3(4):241-249. Available from: http://www.ncbi.nlm.nih gov/pubmed/24596685

29. Ekstrand J, Healy JC, Waldén M, Lee JC, English B, Hägglund $M$. Hamstring muscle injuries in professional football: the correlation of MRI findings with return to play. $\mathrm{Br} \mathrm{J}$ Sports Med. 2012 Feb 1;46(2):112-117. Available from: http://bjsm.bmj. com/content/46/2/112.abstract

30. Ekstrand J, Askling C, Magnusson H, Mithoefer K. Return to play after thigh muscle injury in elite football players: implementation and validation of the Munich muscle injury classification. Br J Sports Med. England. 2013 Aug;47(12):769-774.

31. Patel A, Chakraverty J, Pollock N, Chakraverty R, Suokas AK James SL. British athletics muscle injury classification: A reliability study for a new grading system. Clin Radiol. $2015 \mathrm{Dec}$ [cited 2017 Oct 1];70(12):1414-1420. Available from: http://linkinghub.elsevier.com/retrieve/pii/S000992601500 3554

32. Chan O, Del Buono A, Best TM, Maffulli N. Acute muscle strain injuries: a proposed new classification system. Knee Surg Sports Traumatol Arthrosc. Germany; 2012 Nov;20(11):23562362.

33. Grassi A, Quaglia A, Canata GL, Zaffagnini S. An update on the grading of muscle injuries: a narrative review from clinical to comprehensive systems. Joints. Thieme Medical Publishers; 2016;4(1):39-46. Available from: http://www.ncbi.nlm.nih. gov/pubmed/27386446

34. EIMaraghy AW, Devereaux MW. A systematic review and comprehensive classification of pectoralis major tears. $J$ Shoulder Elbow Surg. 2012 Mar;21(3):412-422. Available from: http://www.sciencedirect. com/science/article/pii/ S1058274611002047

35. Padulo J, Oliva F, Frizziero A, Maffulli N. Muscles, Ligaments and Tendons Journal - Basic principles and recommendations in clinical and field science research: 2016 update. MLTJ. 2016;6(1):1-5. 